$\mathrm{Y}, \mathrm{AK} 314.15: 323(470+571)$

ББК 60.74+66.3(2Poc)

DOI 10.22394/1682-2358-2018-1-47-55

K.S. Mokin, Doctor of Sciences (Sociology), Professor of the Public Administration Department (Graduate School of Public Administration), Balakovo Branch of the Russian Presidential Academy of National Economy and Public Administration

Yu.P. Martsev, Candidate of Sciences (Engineering), Deputy Head of a Department, Volsk Military Institute of Financial Security

\section{PUBLIC PERCEPTION OF MIGRATION AND MIGRANTS IN THE SARATOV REGION UNDER THE INFLUENCE OF GEOPOLITICAL FACTORS}

Based on the ethnological expertise conducted in the region, the main trends in the structure of public perceptions of migration under the influence of geopolitical factors are considered. The changes in the structure of migration flows, the role of geopolitical conflicts in their transformation are recorded. The mutual change in the value-motivational attitudes and behaviors of migrants and the local population (the diffusion of cultures) is analyzed.

Key words and word-combinations: migration, integration, ethnic minorities, interethnic relations, state, ethnic identity.
К.С. Мокин, доктор соииологичеких наук, профессор кафедрьг государственного и муниципального утравления (Вьсшая икола государственного управления) Балаковского филиала Российской академии народного хозяйства и государственной службь при Президенте РФ (email: mokin_konstantin@list.ru)

Ю.П. Мариев, кандидат технических наук, заместитель начальника кафедрь Вольского военного института материального обеспечения (email:martsev65@mail.ru)

\section{ОБЩЕСТВЕННОЕ ВОСПРИЯТИЕ МИГРАЦИИ И МИГРАНТОВ В САРАТОВСКОЙ ОБААСТИ ПОА ВАИЯНИЕМ ГЕОПОАИТИЧЕСКИХ ФАКТОРОВ}

Аннотация. На основе этнологической экспертизы рассмотрены основные тенденции в структуре общественного восприятия миграции под влиянием геополитических факторов. Фиксируется изменение структуры миграционных потоков. Анализируется взаимное изменение ценностно-мотивационных установок и паттернов поведения как со стороны мигрантов, так и местного населения (процесс диффузии культур).

Ключевые слова и словосочетания: миграция, интеграция, этнические меньшинства, межнациональные отношения, государство, этническая идентичность.

Аемографическая характеристика современной России определена рядом существенных факторов, к которым можно 
отнести естественную убыль населения большей части регионов России, возрастающую роль миграции, развитие городских агломераций, в которых проживает более 80\% населения жителей страны. Результаты многолетних исследований показывают, что именно современные города, и в первую очередь мегаполисы, явцяются «точками притяжения» миграционных перемещений (это касается как межрегионацьной, внутристрановой, так и внешней миграции). Города представляют собой перспективные рынки труда, более широкие стратегические возможности трудоустройства, реализаџии человеческого капитала. Реальный спрос на труд (как капитал) в городах на порядки выше, чем в сельских поселениях, где емкость рынка труда ограничена и стоимость работ на порядок ниже, чем в городе, поскольку здесь преобладает низкоквалифиџированный труд. В Саратовской области подавцяющее число мигрантов ориентированы на занятость и проживание в крупных городах региона (Саратов, Энгельс, Балаково, Балашов, Маркс), где осушествмяются крупные инвестиционные и строительные проекты.

Отметим, что, несмотря на декларируемые органами власти позитивные Аостижкения в области демографии, остаются серьезные проблемы воспроизводства экономически активного населения, особенно на региональном уровне. Отсутствие квалифицированной рабочей силы (экономически активного населения) не позволяет в полном объеме использовать экономический потенциал региона, что, в свою очередь, стимулирует привлечение трудовых мигрантов как из Аругих регионов России, так и из стран бывшего СНГ.

В настоящее время, по данным Росстата по Саратовской области [1] , естественная убыль жителей региона за полный 2016 г. (за счет разниџы в уровне рождаемости и уровне смертности) составила 7,4 тыс. чек. (в 2015 - 6,7 тыс.). Родилось 27,3 тыс. чел. (годом ранее - 28,7 тыс.), умерло 34,7 тыс., в том числе 200 младенџев. Таким образом, коэффициент депопумяџии остается значением более 1,57. При этом Саратовская область остается одним из основных пунктов межкународного транзитного миграционного трафика с достаточно низкой собственной миграционной привлекательностью.

Результаты многолетних исследований свидетельствуют о высоком объеме миграционного оттока из Саратовской области в Аругие регионы Российской Федерации. Миграционные устремления жителей региона достаточно четко выражены. Основным детерминирующим фактором выезда из региона является экономическая целесообразность переезда в другие регионы России. Так, $14 \%$ опрошенных заявили о своем желании уехать в Аругой регион на Алительный срок ици на постоянное проживание. Безусловным мидером в выборе территории будущего проживания выступает г. Москва и Московская область, на втором месте - г. С.-Петербург, и на третьем - южное направление (Краснодар, Ростов-на-Аону, Крым и т.А.). Гцавным аспектом миграционной активности (миграционной привлекательности) явцяются значительный уровень доходов в этих городах (территориях), условия и качество жкизни [2] .

Основными вытацкивающими факторами Аця местного насемения явцяются высокий риск потери работы, сокращение реацьного сектора экономики, где занята основная часть населения, снижение уровня заработной пиаты при 
значительном росте стоимости услуг, товаров и цен на продовольственные и промышиенные товары.

Внутрироссийская миграционная убыль региона частично скомпенсирована гражданами, прибывшими из стран СНГ на проживание Саратовскую обмасть. Оттуда в область въехало 10720 чел., покинуло регион 5 614. В «плюсе» регион приобрел 5016 чел., планирующих связать свою жизнь в обозримой перспективе с Россией и Саратовской областью в частности. Больше всего в регионе задержалось граждан Украины (1783), Казахстана (949), Узбекистана (694), Таджикистана (532), Армении (486), Азербайджана (333), Моцаавии (154), Киргизии (138) [2] .

В 2017 г. произошио увеличение транзитных перемещений через регион с целью пересечения государственной границы. Увеличение потока связано с тем, что недавно был ужкесточен контроль на границах с Украиной - в Белгородской и Брянской областях. Именно поэтому поток мигрантов, стремящихся продиить сроки пребывания на территории России, а значит повторным пресечением государственной граниџы, развернулся в сторону Саратовской области, так как контрольный пункт Озинки является для них наиболее удобным и близким. Те, кто за 90 суток законного нахождения на территории страны не успе оформить Аокументы, чтобы продиить срок своего пребывания, делают такой вояж: Аоезжают до сотрудников погранслужб, регистрируются и возвращаются назаА в Россию. Можно сделать промежуточный вывод, что в современных демографических условиях миграционные процессы в регионе (в том числе транзитные) в настоящее время и в обозримой перспективе - еАинственный способ восполнить стареющее экономически активное население [3].

При этом, по оценкам министерства экономики и министерства труда области, сезонная востребованность рабочих в сельском хозяйстве на порядок превосходит преАложение. По официальным данным, услугами гастарбайтеров

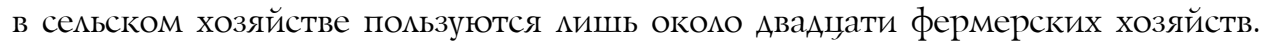
Привлекают в основном жкителей Казахстана, Таджикистана, Узбекистана и Украины. Всего, по официальным оџенкам, около 600 человек из-за рубежка трудятся в Саратовской области. Самое большое коцичество таких хозяйств находятся в Марксовском, Энгельсском, Татищевском и Саратовском районах. В частности, министр труда и миграции области Н. Соколова уточнила, что из 750 вакансий овощеводов (фермерских хозяйств) оказались офиџиально востребованы только 20 [4] .

Реальная картина выглядит иначе. По косвенным оџенкам, только в сельском хозяйстве ежемесячно в период май - сентябрь на полях работают 1,5-3 тысячи граждан зарубежных стран. Более 80\% мигрантов, приезжающих на заработки в Саратовскую область, предпочитают трудоустройство в сфере строительства, в основном в крупных городах региона. Таким образом, реальное число иностранных граждан, занятых в экономической деятельности в регионе, значительно выше, чем официально декларируемые.

Структурные характеристики миграционных процессов таковы: убывают из региона: мица в возрасте 28-45 мет, имеющие средне-специальное или 
высшее образование, практический опыт работы; в потоке выбывших Аоминируют мужчины (55-57\%), женщины (45-43\%), имеющие соџиальный багажк (социальный статус), знающие язык опыт коммуникации и переездов в Аругие города и достаточно адекватно оценивающих свои возможности на внутрироссийском рынке труАа.

Прибывают в регион: мица в возрасте 32-48 мет, в основном мужчины (75-80\%), практически не имеющие социального багажа, опыта коммуникаџии в российском обществе, значительная часть прибывших (более 70\%) не владеют мибо плохо владеют русским языком, имеют минимальный набор профессиональных навыков, образование неполное среднее или среднее (по российским стандартам). Аанная группа оценивает свой труд по минимальным региональным расценкам, что позволяет им демпинговать по заработной плате.

Можно слелать вывод, что миграционные перемещения в / из регион(а) характеризуются неравномерным качеством экономически активного населения. «Вымываются» из региона квалифицированные рабочие кадры, ИТР, а замещаются мигрантами, часто не имеющими даже среАней квацификаџии и испытывающими трудности с соџиализаџией в новом Аля них сообществе.

Не меньшую сложность представцяют геополитические трансформации на постсоветском пространстве и странах, прилегающих к границам бывшего СССР, в частности, сложная ситуация на востоке Украины. Например, с начала конфликтных событий на юго-востоке Украины (Аонецк, Ауганск) в 2014 г. резко возросло число миц, определяемых как бежкенцы (Аанное определение не явцяется вполне корректным, поскольку офиџиально на территории Украины

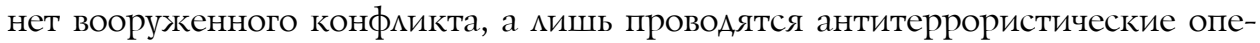
раџии). Значительная часть иммигрантов из Украины в дальнейшем перееха$\Lambda и$ в Аругие регионы России кибо вернулись на родину.

С началом конфликта в Украине Правительство Саратовской области в соответствии с указаниями Правительства РФ предприняло практически все возможкные меры по оказанию помощи беженцам - предоставление жкилья, оказание медиџинской помощи, организаџия питания и т.А. В 2014 г. из средств областного бюджета на помощь беженцам было выделено 91,6 млн руб., в 2015 г. - более 130 млн руб. В 2015 г. быми законодательно опредемены объемы помощи беженцам. По прибытии в регион беженџы (вкцючая чиенов семьи, детей) получали 1,5 тыс. руб. "подъемных», на каждого выдемялось по 800 руб. в сутки «на содержание» на каждого чмена семьи (из них 250 руб. - на питание).

Специфичность ситуации закцючается в том, что на начальном этапе жките$\Lambda и$ региона оказывали посильную помощь беженцам - предоставцяли жкилье, еду, оказывали транспортную помощь. ОАнако с середины - конца 2015 г. в регионе начали распространяться негативные мнения об «украинских мигрантах»: «они не хотят работать», «они пьют и ничего не Аелают» и т.п. Аефакто жкители региона столкнулись с избирательной политикой соџиальной подАержки. В частности, 800 руб. ежкесуточных среАств подАержки на одного человека (мигранта) часто превышал суточный Аоход местных жкителей (в 
среднем жители региона в день зарабатывают 450-550 руб.), что негативно сказалось на цегитимации деятельности властей по подАержке мигрантов из Украины.

В 2016 г. поток бежкенцев из Аонецкой и Ауганской областей, по данным МВА, остановицся. Большинство из них оформици российское гражАанство, расселились у родственников или вернулись на Украину. В связи с этим правительство решило с 1 января 2017 г. закрыть пункты их временного размещения. Если в начале 2015 г. в России действовали 576 пунктов размещения, то к концу 2016 их почти не осталось. В Саратовской области продолжает

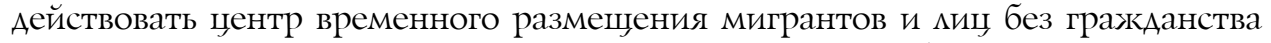
(г. Энгельс). В настоящее время в нем находятся более 500 человек (в основном из стран Центральной и Юго-Восточной Азии), в том числе 20 беженџев из Сирии. Граждане (бежкенџы) с Украины в центре не размещаются.

ОАним из наиболее сложных вопросов остается проблематика взаимоотношений межау мигрантами и местным населением региона. Результаты проведенных в 2016-2017 гг. соџиологических исследований показывают, что значительная часть населения (78\%) имеет опыт мичных контактов с мигрантами - выходцами из Аругих стран [5; 6]. При этом пятая часть опрошенных (20\%) положительно оценивают роль мигрантов в жкини региона (его социально-экономическом развитии), более четверти (26\%) считают, что мигранты оказывают влияние на развитие территории, но в незначительной мере. Почти треть (31\%) из числа имеющих опыт межличностных контактов с мигрантами отметили, что поведение последних полностью или в целом соответствует общепринятым нормам сощиального поведения жителей региона. Примерно столько же (32\%) дали нейтрально-отрицательную оценку поведению мигрантов, и 31\% отметили их поведение как не соответствующее общепринятым нормам.

Адаптация и интеграция мигрантов (инокультурных) протекает в весьма сложных отношениях с принимающим (местным) населением. Несмотря на Аоминирующий в регионе Аискурс, где мигранты представлены еАва $и и$ не угрозой существующему социальному, культурному и экономическому уклаАу жкизнедеятельности местного населения, респонденты отмечают нейтрацьносдержканное отношение к мигрантам.

В обыденном понимании жкителей региона «видимый» мигрант - это в первую очередь фенотипически отличный человек, говорящий на Аругом языке, с поведением, отличающимся от общепринятых канонов и соџиальных норм. Гражданство (нацичие паспорта, знание языка) часто не явцяется кцючевым маркером «своего». Азербайджанец, приехавший в страну в период распада СССР и проживший в городе более 25 мет, имеющий высшее образование, но фенотипично отличающийся от общей массы, - все равно «мигрант». Казахи, к облику которых все привыкли в приграничном районе, чаще считается «своим».

Характерной чертой, навязанной в основном меАийным Аискурсом, явмяется представленность мигрантов в криминогенной сфере. На наш взгляА, ответы респондентов о распространенности «этнической преступности» яв- 
мяются проекцией отдельных фактов, изложенных в прессе и ТВ (чаще всего федерального и регионального уровней). Более значима роль и «сарафанного радио» (слухов, сплетен, сосеАских интерпретаций) в обобщенном представ-

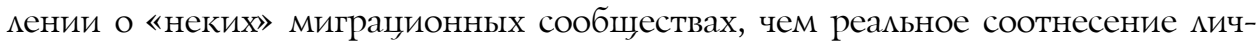
ного опыта общения с мигрантами и фактическое участие «знакомых мигрантов» в криминале.

Тем не менее, несмотря на существующий в публичном дискурсе негатив в отношении мигрантов, более половины опрошенных отАают себе отчет в необходимости привлечения новых рабочих рук и, соответственно, положительно-нейтрацьно относятся к возможности трудоустройства мигрантов в регионе. Чаще всего мигранты воспринимаются местным населением как мица, имеющие низкую профессионацьную подготовку, но с Аостаточно высоким уровнем трудолюбия и высокой степенью готовности к поиску работы (новых мест работы) и к дальнейшим миграционным перемещениям ради более высокого заработка (прейти на новое место, переехать в Аругой населенный пункт, Аругой гороА, Аругую область).

На основании исследований можно сделать вывод, что восприятие мигрантов в целом как «воображаемого сообщества» строится чаще всего на существующем дискурсе, артикулируемом фелеральными, региональными и местными СМИ. Так, на вопрос, отнимают $и$ приезжие из Аругих государств рабочие места у местных жкителей, почти четверть респондентов (22\%) убежденно разделяют эту точку зрения. ОАнако $40 \%$ отметици, что сами «местные» не хотят занимать эти рабочие места (как правицо, малооплачиваемые и малопрестижные), и еше почти треть респондентов согласицось и с первым, и вторым доводом (табл. 1).

Таблища 1

Как вам кажкется, приезжие из Аругих государств отнимают работу у местных жителей? (\% от числа опрошенных)

\begin{tabular}{c|l|c}
\hline 1 & Приезжие отнимают работу у местных жителей & 22,0 \\
\hline 2 & Местные жители сами не хотят занимать некоторые рабочие места & 39,7 \\
\hline 3 & И то, и другое & 29,7 \\
\hline 4 & Другой ответ & 1,7 \\
\hline 5 & Затрудняюсь ответить & 7,0
\end{tabular}

Как слеАствие, респонденты видят мигрантов в самых «нижних» отрасмях (сферах) городской и региональной экономики: уборка и Аругие услуги ЖKX (40\%), строительство и дорожные работы (36\%), сельское хозяйство (27\%), работа по найму у граждан (13\%). Тем не менее почти четверть опрошенных (24\%) твердо заявили, что ни в никаких профессиях мигранты не нужны. ПослеАняя группа представлена в основном старшим поколением

* Опрос в рамках проекта «Механизмы обеспечения гражданского согласия в многоэтничных государствах: российский и зарубежный опыт» (грант РНФ №15-18-00099). Опрошены 650 чел. Выборка квотная , репрезентативна по возрасту, полу , территории проживания.

52 Bulletin of the Volga Region Institute of Administration • 2018. Vol. 18. № 1 
жителей региона, и обладающая «устойчивыми» стереотипами восприятия мигрантов (табл. 2).

Таблица 2

В каких профессиях следует использовать труА иностранных мигрантов в вашем регионе? (\% от числа опрошенных, нескомько вариантов ответа)

\begin{tabular}{c|l|c}
\hline 1 & Уборка и другие жилищно-коммунальные услуги & 38,7 \\
\hline 2 & Использовать в строительстве, дорожных работах & 36,0 \\
\hline 3 & Охрана парковок, магазинов & 9,3 \\
\hline 4 & Торговля & 11,3 \\
\hline 5 & Общественный транспорт & 4,0 \\
\hline 6 & Заводы, фабрики & 11,3 \\
\hline 7 & Сельское хозяйство & 27,3 \\
\hline 8 & Кафе, рестораны, гостиницы & 5,7 \\
\hline 9 & Медицина, социальные услуги & 4,0 \\
\hline 10 & $\begin{array}{l}\text { Работа по найму у граждан } \\
\text { (на приусадебных участках, няни в семьях и др.) }\end{array}$ & 13,0 \\
\hline 11 & Ваш вариант & 3,3 \\
\hline 12 & Ни в каких профессиях мигранты не нужны & 23,7 \\
\hline 13 & Затрудняюсь ответить & 4,7 \\
\hline
\end{tabular}

В общем объеме $72 \%$ респондентов высказались о потенщиальной необходимости использования труда мигрантов в регионе. Восприятие мигрантов как низкокачественной, Аешевой и безропотной рабочей симе, сформированное существующим Аискурсом, проявмяется в разного рода полукриминальных практиках найма, жестких условиях работы, невыплате заработной платы.

Интеграџия мигрантов в соџиально-культурное, общественно-политическое поле мокального сообщества всегда связана с определенными трудностями как дмя самих мигрантов, так и Аля принимающего насемения. В этом отношении одним из инструментов инкАюзии является и привлечение мигрантов к участию в общественной жизни сообщества (квартала, района города, села), и информирование мигрантов о правиках поведения, практиках использования общественного транспорта, отношений между мюдьми (повседневным этикетом). Более $35 \%$ респондентов считают, что оптимальным способом интеграџии в жизнь сообщества бымо бы активное участие в общественной / публичной жизни, еше столько же считают, что можно совместить и участие в жизни сообщества, и представить мигрантам информаџионные материалы (Аистовки, буклеты и т.п.). Часто респонденты отмечали необходимость созАания специализированных центров по поддержке в аАаптации мигрантов как на базе учебных заведений, так и на базе НКО. 
ОАним из кАючевых «камней преткновения» в проџессе взаимодействия «мигрант - местный житель» явмяется требование к знанию русского языка. Отмечая значимость русского языка как маркера отношений между инокультурными мигрантами и местным населением, отметим следующее. Более трети (36\%) респондентов считают, что необходимо обучать инокультурных трудовых мигрантов русскому языку, не артикулируя условия и возможности обучения. Почти такая же часть опрошенных (30\%) согласилась с этим, но при условии, что все затраты на обучение будут нести сами мигранты. Почти

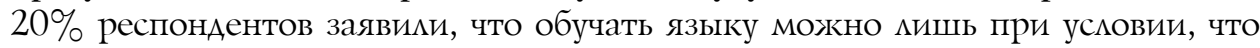
мигранты ориентированы на постоянное проживание в России.

В настоящее время Саратовская область, несмотря на эпизодические конфмикты и стычки межАу местным населением и мигрантами, явмяется достаточно устойчивой к проявлению радикальных форм мигрантофобии. Население региона в целом демонстрирует достаточно высокий потенциал позитивного взаимодействия.

Таким образом, опираясь на полученные результаты серии исследований, можно сделать ряА выводов.

Во-первых, в отношении мигрантов, прибывших на территорию Саратовской области, Аоминирует позитивно-нейтральная оџенка.

Во-вторых, основной причиной фобий и страхов в отношении мигрантов остается «бытовой культурный диссонанс», опредемяемый как несоответствие культурных норм и повседневных практик поведения, особенно в публичных местах и местах «социального напряжения» (рынки, базары и т.А.).

B-третьих, характерной чертой, формирования кросскультурного взаимодействия является доминирующий антимиграционный медийный дискурс.

В-четвертых, причиной устойчивости фобий явмяются проекции отдельных фактов, изможенных в прессе и ТВ (чаще всего федерального и регионального уровней, редко местного), а также мнение «сарафанного радио» (слухи, сплетни, «соседские интерпретации») на обобщенное преАставление о «неких» миграџионных сообществах, Миграционные сообщества в общественном восприятии при проведении опроса представлялись респондентами как некая абстрактная общность, «воображаемое сообщество».

В-пятых, наблюдается ряд практик, которые в цемом можно назвать «выдавливание», «создание невидимости «иных», требований подчиненности и Аиктата доминирующих в сообществе норм и паттернов поведения. Мигранты, как правило, маркируются как мюди «второго сорта», «выходџы из стран третьего» мира, не имеющие прав, обязанные выполнять мишь функциональные задачи. В противовес этому мигранты формируют практики солидаризации, требования признания равности с местным населением, требования учета собственных культурных особенностей и притязаний, а также прилагают все усилия по институџионализаџии «реальных» практик защиты себя и своих семей от культурного, соџиального, экономического и политического Аавления (принудительного) со стороны доминирующего местного населения.

В-шестых, анализ результатов исследований убедительно показывает, что в доминирующем дискурсе мигранты воспринимаются как своего рода необхо-

54 Bulletin of the Volga Region Institute of Administration • 2018. Vol. 18. № 1 
димый, но пока еще побочный трудовой ресурс. Предможкенная респондентам модель создания системы центров поддержки и обучения мигрантов показывает, что, несмотря на свою востребованность, в определенной части она будет способствовать не столько интеграции, сколько сепарации.

В-седьмых, появление мигрантов в малооплачиваемых, невостребованных местным населением сегментах рынка труда не вызывает негатива, поскольку укмадывается в сформированную дискурсом модель социальных отношений «местное население - мигрант». Аанная модель отношений не предусматривает прямой конкуренции мигрантов и местного населения за высокоопмачиваемые места и не несет (со стороны мигрантов) угрозы соџиальному, экономическому, культурному и политическому статусу большинства. Аанная модель строится из стремления большинства сделать мигрантов "невидимыми» в пубиичной сфере и отчасти направлена искмючительно на прагматическое использование дешевой рабочей силы, без предоставления мигрантам равных с большинством прав, свобод и возможностей.

В-восьмых, в условиях сохраняюшейся динамики миграционных процессов, и роста этнокультурного разнообразия, появления новых форм (ре)презентации этнокультурных меньшинств, появления этнически окрашенных сегментов рынка (торговця, малый бизнес, автосервис и т.А.) приемцемым вариантом видится использование имеющихся наиболее эффективных инструментов этнокультурной политики (например, региональных и местных СМИ), которые позволили бы расширить интеграционный потенциал местных житемей, за счет расширения представлений плюсов культурного, этнического и мингвистического разнообразия.

\section{Библиографический список}

1. Данные Росстата по Саратовской области. URL: http://www.gks.ru/free_doc/new_site/ population/trud/migrac/mtm_2016.pdf

2. Мокин К.С., Барышная Н.А. Общественное восприятие миграции в контексте социальных отношений: миграция - ресурс или угроза? // Актуальные проблемы современности: наука и общество. 2017. № 3 (16). С. 3-10.

3. Молчанова Е.В., Кручек М.М., Кибисова 3.С. Построение рейтинговых оценок субъектов Российской Федерации по блокам социально-экономических показателей // Экономические и социальные перемены: факты, тенденции, прогноз. 2014. № 3 (33). С. 196-208.

4. Кравиева T., Соколова H. Саратовская область не может обойтись без овощеводов-гастарбайтеров. URL: https://fn-volga.ru/news/view/id/74591

5. Барышная Н.А. Механизмы совершенствования региональной миграционной и этнокультурной политики (на примере Саратовской области) // Вестник Поволжского института управления. 2014. № 2 (41), С. 9-15.

6. Социальные факторы этнической нетерпимости (итоги междисциплинарного исследования) / под ред. В.В. Степанова, В.А. Тишкова. М., 2014. 